\title{
FATORES DE RISCO E CLASSIFICAÇÃO CLÍNICA ASSOCIADOS À SOROPOSITIVIDADE PARA LEISHMANIOSE VISCERAL CANINA
}

\author{
Márcia Janete de Fátima Mesquita de Figueiredo ${ }^{1}$, NAZARÉ Fonseca de Souza ${ }^{2}$, Heriberto

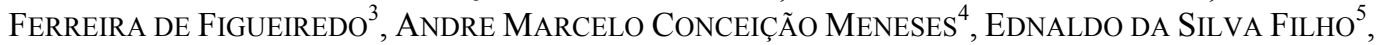 \\ GLÁUCIA GRAZIELE NASCIMENTO ${ }^{6}$
}

\footnotetext{
${ }^{1}$ Médica Veterinária, Mestre da Universidade Federal Rural da Amazônia, Belém, PA, Brasil. marcia.figueiredo@ufra.edu.br ${ }^{2}$ Professora Doutora da Universidade Federal Rural da Amazônia, Belém, PA, Brasil.

${ }^{3}$ Médico Veterinário, Mestre da Universidade Federal Rural da Amazônia, Belém, PA, Brasil.

${ }^{4}$ Professor Doutor da Universidade Federal Rural da Amazônia, Belém, PA, Brasil.

${ }^{5}$ Professor Doutor da Universidade Federal Rural da Amazônia, Belém, PA, Brasil.

${ }^{6}$ Médica Veterinária, Pós-graduanda, Universidade Federal Rural de Pernambuco, Recife, PE, Brasil.
}

Com o objetivo de avaliar os fatores de risco e a classificação clínica associados à soropositividade para Leishmaniose Visceral Canina (LVC) no município de Colares, estado do Pará, foram coletadas e analisadas 435 amostras de soro sanguíneo de cães de ambos os sexos, idade a partir de 4 meses, com ou sem de raça definida e com ou sem sintomatologia clínica sugestiva da doença, dos bairros e das localidades da zona rural. A sorologia foi realizada empregando-se os métodos Ensaio Imunoenzimático (ELISA/S7) e Reação de
Imunofluorescência Indireta (RIFI), em lâminas fixadas com antígenos de Leishmania infantum. O sexo não apresentou significância estatística $(\mathrm{P}>0,05)$. Observouse prevalência significativa de LVC com relação à faixa etária e classificação clínica $(\mathrm{P}<0,05)$. A prevalência foi maior para cães na faixa etária menor de 2 anos e para os classificados clinicamente como sintomáticos, sendo que onicogrifose e alterações cutâneas foram as alterações clínicas mais frequentes.

PALAVRAS-CHAVE: cães; Estado do Pará; fatores de risco; leishmaniose visceral; soropositividade.

\section{RISK FACTORS AND CLINICAL CLASSIFICATION ASSOCIATED WITH SEROPOSITIVITY FOR CANINE VISCERAL LEISHMANIASIS}

\section{ABSTRACT}

In order to evaluate the risk factors and clinical classification associated with seropositivity for Canine Visceral Leishmaniasis (CVL) in the city of Colares, Pará State, 435 serum samples were collected from dogs of both sexes, aged from 4 months, with or without standard breed and with or without clinical symptoms suggestive of disease, from the neighborhoods and the rural areas, and analyzed. Serology was performed using immunoenzymatic assay (ELISA/S7) and
Immunofluorescence Assay (IFA) methods in fixed slides with antigens from Leishmania infantum. Sex did not present statistic significance $(\mathrm{P}>0.05)$. There was significant prevalence of LVC regarding age and clinical classification $(\mathrm{P}<0.05)$. The prevalence was higher for dogs aged less than 2 years and for those classified as clinically symptomatic, and onychogryphosis and skin changes were the most common clinical changes.

KEYWORDS: dogs; Pará State; risk factors; seropositivity; visceral leishmaniasis. 


\section{INTRODUÇÃO}

Em Medicina Veterinária, a Leishmaniose Visceral Canina (LVC) é a zoonose mais importante, pois além da doença ser, na maioria dos casos, severa e fatal para o cão, este é ainda o reservatório da doença para os humanos (1). Os cães têm sido incriminados como o principal reservatório da doença, pois preenchem as condições necessárias para isso, por serem altamente susceptíveis à infecção, por possuírem elevado parasitismo cutâneo e, principalmente, devido à sua estreita relação com o homem, tanto em áreas rurais, como urbanas (2).

A LVC é uma doença complexa, sistêmica, crônica e até mesmo fatal, caracterizada por alterações clínicas muito variáveis, envolvendo quase todos os órgãos, em consequência da multiplicidade de mecanismos patogênicos do protozoário, da diversidade de respostas imunológicas desenvolvidas nos hospedeiros e do longo período de incubação, que pode variar de alguns meses até vários anos. A complexidade da doença faz com que, ainda hoje, mais de cem anos após sua descoberta, não haja completo consenso científico sobre o seu manejo $(3,4)$.

Os resultados das pesquisas variam de acordo com as características da população, a metodologia empregada na avaliação, além dos fatores de riscos associados à infecção como sexo, faixa etária, raça, tamanho e tipo do pelame, estado geral, sintomatologia clínica e condições do peridomicílio, em que a maior incidência parece estar associada às moradias próximas de matas e a convivência com outros animais domésticos e selvagens (5).

O objetivo deste estudo foi avaliar os fatores de risco e a classificação clínica associados à soropositividade para LVC, no município de Colares, região Nordeste do estado do Pará.

\section{MATERIAL E MÉTODOS}

O município de Colares, no estado do Pará, tem o seu litoral banhado pela Baía de Marajó, pertence à Mesorregião do Nordeste Paraense e Microrregião do Salgado, distante $90 \mathrm{~km}$ da capital Belém. Faz limite ao Norte com Baía de Marajó e município de Vigia, a Leste com município de Vigia, ao Sul com município de Santo Antônio do Tauá e a Oeste com a Baía de Marajó (6).

Foram selecionados aleatoriamente, para a coleta de sangue, 435 (quatrocentos e trinta e cinco) cães (Canis familiaris) domiciliados nos bairros e nas localidades da zona rural do município de Colares, de ambos os sexos, idade acima de quatro meses, com ou sem raça definida. Todos os cães foram examinados para verificar a presença de sinais clínicos sugestivos de LVC e foram classificados como sintomáticos quando apresentaram uma alteração clínica sugestiva da doença, tais como perda de peso, alterações cutâneas, alterações oculares, linfoadenomegalia e onicogrifose. Por outro lado, cães sem qualquer sinal foram avaliados como assintomáticos, considerando, como foi mencionado por Reis et al. (7), que os sinais clínicos iniciais associados à LVC são linfoadenomegalia, dermatite periorbital e nasal ou disseminada, onicogrifose e perda de peso. A perda de peso foi assim identificada pelas informações dos proprietários e observada pelo escore corporal. Para alterações cutâneas foram consideradas, principalmente, as condições de pelo sem brilho, com alopecia e dermatites e, pra alterações oculares, considerou-se a presença de secreção. Linfoadenomegalia foi determinada quando na inspeção era observado um aumento dos linfonodos, confirmado pela palpação, e a onicogrifose foi avaliada por meio do crescimento anormal das unhas.

As análises das amostras de soro dos animais investigados foram realizadas no período de abril a maio de 2012, no Laboratório de Doenças Parasitárias dos Animais Domésticos (LDP), da Universidade Federal Rural de Pernambuco (UFRPE), localizado na cidade de Recife - PE. Os anticorpos anti-Leishmania foram detectados por meio dos métodos sorológicos ELISA e RIFI. Para o ELISA, utilizou-se o Kit para Diagnóstico do Calazar Canino - ELISA $/ S 7^{\circledR}$, produzido por Biogene Indústria e Comércio Ltda. A reação foi realizada de acordo com o protocolo do fabricante, sendo considerados reagentes os soros que apresentaram o valor de densidade óptica igual ou superior a três desvios padrão do ponto de corte. Para a RIFI, foram utilizadas lâminas de vidro contendo 12 poços, fixadas com antígenos de Leishmania infantum, procedentes do Instituto de Tecnologia em Imunobiológicos Bio-Manguinhos, da Fundação Oswaldo Cruz. A técnica foi realizada de acordo com Camargo (8), considerando reagente o soro que apresentou fluorescência na titulação de 1:40, como preconiza o Ministério da Saúde, tomando-se como referência para as amostras reagentes e não reagentes os soros controle positivo e negativo, provenientes do LDP - UFRPE, que foram incluídos em cada lâmina. Todas as amostras de soro sanguíneo dos cães foram analisadas pelos dois métodos sorológicos ELISA/S7 e RIFI.

As análises estatísticas foram realizadas de forma descritiva e foram aplicados o Teste de QuiQuadrado e Odds ratio $(\mathrm{OR})$ com nível de significância 
de 5\%. Todas as análises estatísticas foram realizadas pelo programa computacional BioEstat 5.0 (9)

Esse estudo foi apreciado e aprovado pelo Comitê de Ética no Uso de Animais (CEUA) da Universidade do Estado do Pará (UEPA), registrado no protocolo $\mathrm{N}^{\circ} 48 / 11$.

\section{RESULTADOS E DISCUSSÃO}

As variáveis sexo, faixa etária e classificação clínica associadas à soropositividade nas reações ELISA+RIFI para Leishmaniose Visceral Canina estão apresentadas na Tabela 1.

Observa-se que para a variável sexo não houve prevalência significativa $(\mathrm{P}>0,05)$; contudo, na análise dos dados das variáveis faixa etária e classificação clínica foi comprovada prevalência significativa $(\mathrm{P}<$ $0,05)$, evidenciando-se que, na faixa etária menor que dois anos, os cães tem uma chance sete vezes maior de serem soropositivos que os da faixa etária maior que 2 anos. Na classificação clínica, foi demonstrado que os cães sintomáticos têm cerca de três vezes mais chance de serem soropositivos em relação aos assintomáticos.

A variável raça não foi analisada estatisticamente, pois todos os cães soropositivos nas reações ELISA+RIFI para LVC apresentavam-se sem padrão de raça definida.

Tabela 1 - Variáveis sexo, faixa etária e classificação clínica associadas à soropositividade nas reações ELISA+RIFI para Leishmaniose Visceral Canina - 2013

\begin{tabular}{|c|c|c|c|c|c|}
\hline Variáveis & $\mathrm{N}$ & $+(\%)$ & OR & IC $95 \%$ & $\mathrm{P}$ \\
\hline \multicolumn{6}{|l|}{ Sexo } \\
\hline Macho & 250 & $25(10,0)$ & \multirow{2}{*}{1,03} & \multirow{2}{*}{$0,54-1,95$} & \multirow{2}{*}{0,94} \\
\hline Fêmea & 185 & $18(9,7)$ & & & \\
\hline \multicolumn{6}{|l|}{ Faixa etária } \\
\hline$<2$ anos & 236 & $24(10,2)$ & \multirow{2}{*}{6,98} & \multirow{2}{*}{$3,47-14,04$} & \multirow{2}{*}{$0,0001^{*}$} \\
\hline$>2$ anos & 199 & $19(9,5)$ & & & \\
\hline \multicolumn{6}{|l|}{ Classificação clínica } \\
\hline Sintomáticos & 223 & $32(14,3)$ & \multirow{2}{*}{3,06} & \multirow{2}{*}{$1,50-6,25$} & \multirow{2}{*}{$0,002 *$} \\
\hline Assintomáticos & 212 & $11(5,2)$ & & & \\
\hline
\end{tabular}

Vários estudos tentam avaliar os fatores de risco associados à infecção em cães no Brasil, principalmente aqueles inerentes ao cão, como sexo, faixa etária, raça, tamanho e tipo do pelame, estado geral e sintomatologia clínica e, mais ainda que as discordâncias aparentes entre os estudos possam refletir na natureza local da LVC (5).

Com relação à variável sexo, os resultados aqui encontrados estão de acordo com Almeida et al. (10) e Santos et al. (11), que não observaram predisposição sexual. Todavia, Julião et al. (12) e Medeiros et al. (13) observaram predisposição nos cães machos, enquanto que Amóra et al. (14) encontraram percentual maior entre as cadelas do meio rural.

Quanto à variável faixa etária, os dados aqui referidos estão em concordância com os de DantasTorres et al. (15) e Medeiros et al. (13), que observaram uma positividade sorológica estatisticamente significativa nos cães jovens, o que pode estar associado à imaturidade imunológica, tornando-os bastante vulneráveis para contrair a infecção e evoluir para doença sintomática, com a positividade sendo mais facilmente observada nas reações sorológicas. Porém, esse resultado discorda dos encontrados por Almeida et al. (10), que descreveram ser mais frequente em cães adultos, como também aos de Santos et al. (11) e Silva et al. (16) de que não há predisposição quanto à idade.

A variável raça não foi analisada estatisticamente, pois todos os cães sororeagentes apresentavam-se sem de raça definida, pois, como afirma Dantas-Torres (5), a maioria dos cães que vivem em áreas rurais e suburbanas são cães sem raça definida. Contudo, em alguns estudos como os realizados por Medeiros et al. (13) e Silva et al. (16), esta variável foi analisada, mas não se observou significância estatística quanto à soropositividade. 
Por outro lado, França-Silva et al. (17) encontraram uma maior prevalência para os cães de raça Cocker Spaniel e Boxer.

No que se refere à variável categorização clínica, os cães foram classificados como assintomáticos e sintomáticos, quando apresentaram pelo menos uma alteração clínica sugestiva da doença e tiveram como parâmetros analisados perda de peso, alterações cutâneas, alterações oculares, linfoadenomegalia e onicogrifose. Os cães sororeagentes demonstraram expressiva significância estatística para a forma sintomática da LVC, concordando com os estudos realizados por Sousa e Almeida (18) e Almeida et al. (10), nos quais os cães infectados encontravam-se sintomáticos.

A frequência dos sororeagentes nas reações ELISA e RIFI, baseando-se nas alterações clínicas observadas nos cães, estão apresentadas na Tabela 2. Os cães que apresentaram pelo menos uma alteração clínica sugestiva de LVC, como perda de peso, alterações cutâneas, alterações oculares, linfoadenomegalia e onicogrifose, foram considerados animais sintomáticos. Onicogrifose e alterações cutâneas foram as que apresentaram maiores porcentagens, 23,3 e $14,4 \%$, respectivamente.

Todavia Baneth e Aroch (19) afirmam que estudos populacionais em áreas endêmicas têm demonstrado que uma proporção da população canina desenvolve a doença sintomática, outra tem infecção assintomática persistente, enquanto outra é resistente à infecção ou intermitentemente resolve sem desenvolver sinais clínicos. Já para Moshfe et al. (20), estudos soroepidemiológicos da LVC têm revelado um grande número de animais soropositivos assintomáticos, dessa forma, os cães assintomáticos infectados por Leishmania, bem como os sintomáticos, podem ter um papel importante na manutenção da infecção e, provavelmente, no estabelecimento do ciclo doméstico de transmissão do parasita nas áreas endêmicas de LV.

Tabela 2 - Frequência dos sororeagentes no ELISA e RIFI, baseados nas alterações clínicas dos cães

\begin{tabular}{lccc}
\hline Alterações Clínicas & $\mathrm{N}$ & + & $\%$ \\
\hline Perda de peso & 40 & 04 & 10,0 \\
Alterações cutâneas & 132 & 19 & 14,4 \\
Alterações oculares & 10 & 01 & 10,0 \\
Linfoadenomegalia & 11 & 01 & 9,1 \\
Onicogrifose & 30 & 07 & 23,3 \\
\hline
\end{tabular}

n (número total de animais); + (número de animais soropositivos); \% (frequência)

As alterações clínicas mais frequentes entre os cães sororeagentes foram onicogrifose $\mathrm{e}$ alterações cutâneas à semelhança do que Azevedo et al. (4) e Dias et al. (22) relataram em seus estudos.

\section{CONCLUSÃO}

A sorologia positiva para LVC não foi relacionada com as variáveis sexo e raça, porém, está associada à faixa etária e à classificação clínica, na qual os cães classificados como sintomáticos que apresentaram onicogrifose e alterações cutâneas foram os mais frequentes.

\section{AGRADECIMENTOS}

À Prefeitura Municipal de Colares, pelo apoio e compromisso na realização dos trabalhos de campo, ao Laboratório de Doenças Parasitárias dos Animais Domésticos da Universidade Federal Rural de Pernambuco, pelo processamento das amostras sorológicas e ao Programa de Cooperação Acadêmica - Novas Fronteiras (PROCAD-NF UFRA-UFRPE-UNESP Botucatu), com apoio da CAPES/MEC, pelo suporte financeiro. 
Parasitology. 2008; 24(7):324-330.

4. Solano-Gallego L, Miró G, Koutinas A, Cardoso L, Pennisi MG, Ferrer L, Bourdeau P, Oliva G, Baneth G. LeishVet guidelines for the practical management of canine leishmaniosis. Parasites \& Vectors. 2011;4(86):116.

5. Dantas-Torres F. Canine leishmaniosis in South America. Parasites \& Vectors. 2009;2(1):1-8.

6. IDESP Instituto do Desenvolvimento Econômico, Social e Ambiental do Pará. Secretaria de Estado de Planejamento. Estatística Municipal - Colares, 2012. Disponível em: < http://www.idesp.pa.gov.br/paginas/produtos/EstatisticaM unicipal/pdf/Colares.pdf $>$.

7. Reis AB, Martins-Filho OA, Teixeira-Carvalho A, Giunchetti RC, Carneiro CM, Mayrink W, Tafuri WL, Corrêa-Oliveira R. Systemic and compartmentalized imune response in canine visceral leishmaniasis. Veterinary Immunology and Immunopathology. 2009;128(1-3)y:87-95.

8. Camargo ME. Introdução às técnicas de imunofluorescência. Revista Brasileira de Patologia Clínica. 1974;10(1):143-169.

9. Ayres M, Ayres Jr M, Ayres DL, Santos AAS. Bioestat: aplicações estatísticas nas áreas das Ciências Biomédicas. Versão 5.0. Belém, Pará: Sociedade Civil Mamirauá, MCT-CNPq, 2007. 324 p.

10. Almeida ABPF, Mendonça AJ, Sousa VRF. Prevalência e epidemiologia da leishmaniose visceral em cães e humanos, na cidade de Cuiabá, Mato Grosso, Brasil. Ciência Rural. 2010;40(7):1610-1615.

11. Santos JML, Dantas-Torres F, Mattos MRF, Lino FRL, Andrade LSS, Souza RCA, Brito FLC, Brito MEF, Brandão-Filho SP, Simões-Mattos L. Prevalência de anticorpos anti-Leishmania spp em cães de Garanhuns, Agreste de Pernambuco. Revista da Sociedade Brasileira de Medicina Tropical. 2010;43(1):41-45.

12. Julião FS, Souza BMPS, Freitas DS, Oliveira LS, Laranjeira DF, Dias-Lima AG, Souza VMM, BarrouinMelo SM, Moreira Jr ED, Paule BJA, Franke CR. Investigação de áreas de risco como metodologia complementar ao controle da leishmaniose visceral canina. Pesquisa Veterinária Brasileira. 2007;27(8):319324.

13. Medeiros CFO, Melo AGC, Lima AKF, Silva ING, Oliveira LC, Silva MC. Perfil hematológico de cães com leishmaniose visceral no município de Fortaleza, Ceará. Ciência Animal. 2008;18(1):33-40.

14. Amóra SSA, Santos MJP, Alves ND, Costa SCG, Calabrese KS, Monteiro AJ, Rocha MFG. Fatores relacionados com a positividade de cães para leishmaniose visceral em área endêmica do Estado do Rio Grande do Norte, Brasil. Ciência Rural. 2006;36(6):1854-1859.

15. Dantas-Torres $\mathrm{F}$, Brito $\mathrm{MEF}$, Brandão-Filho SP. Seroepidemiological survey on canine leishmaniasis among dogs from an urban area of Brazil. Veterinary Prasitology. 2006;140(1-2):54-60.

16. Silva FTS, Santos JT, Netto EM, Bavia ME, Nakatani M, Souza FDP, Cardim LL, Carneiro DDMT. Aspectos clínicos da Leishmaniose Visceral canina no Distrito de Monte Gordo, Camaçari (BA). Revista Baiana de Saúde Pública. 2010;34(4):783-795.

17. França-Silva JC, Costa RT, Monteiro EM, MachadoCoelho GLL, Vieira EP, Prata A, Mayrink W, Nascimento E, Forte-Dias CL, Silva JC, Dias ES. Epidemiology of canine visceral leishmaniosis in the endemic area of Montes Claros Municipality, Minas Gerais State, Brazil. Veterinary Parasitology. 2003;111(2-3):161-173.

18. Sousa VRF e Almeida ABPF. Co-infecção entre leishmaniose visceral e ehrlichiose monocítica em cães de Cuiabá, Mato Grosso. Acta Scientiae Veterinarie. 2008;36(2):113-117.

19. Baneth $G$ e Aroch I. Canine leishmaniasis: a diagnostic and clinical challenge. The Veterinary Journal. 2008;175(1):14-15.

20. Moshfe A, Mohebali M, Edrissian G, Zarei Z, Akhoundi B, Kazemi B, Jamshidi S, Mahmoodi M. Canine visceral leishmaniasis: Asymptomatic infected dogs as a source of $L$. infantum infection. Acta Tropica. 2009;112(2):101-105.

21. Azevedo MAA, Dias AKK, De Paula HB, Perri SHV, Nunes CM. Avaliação da Leishmaniose Visceral Canina em Poxoréo, Estado do Mato Grosso, Brasil. Revista Brasileira de Parasitologia Veterinária. 2008;17(3):123127.

22. Dias EL, Batista ZS, Guerra RMSNC, Calabrese KS, Lima TB, Abreu-Silva AL. Canine visceral leishmaniasis (CVL): seroprevalence, clinical, hematological and biochemical findings of dogs naturally infected in an endemic area of São José de Ribamar municipality, Maranhão state, Brazil. Ciência Animal Brasileira. 2008;9(3):740-745. 